\title{
A neutrophil elastase inhibitor, sivelestat, ameliorates lung injury after hemorrhagic shock in rats
}

\author{
YUICHIRO TODA ${ }^{1}$, TORU TAKAHASHI ${ }^{1}$, KYOICHIRO MAESHIMA ${ }^{1}$, HIROKO SHIMIZU $^{1}$, \\ KAZUYOSHI INOUE ${ }^{1}$, HIROSHI MORIMATSU ${ }^{1}$, EMIKO OMORI ${ }^{1}$, MAMORU TAKEUCHI ${ }^{1}$, \\ REIKO AKAGI ${ }^{2}$ and KIYOSHI MORITA ${ }^{1}$
}

\author{
${ }^{1}$ Department of Anesthesiology and Resuscitology, Okayama University Medical School, 2-5-1 Shikata-cho, \\ Okayama, Okayama 700-8558; ${ }^{2}$ Department of Nutritional Science, Okayama Prefectural University, \\ 111 Kuboki, Soja, Okayama 719-1197, Japan
}

Received September 25, 2006; Accepted November 2, 2006

\begin{abstract}
Hemorrhagic shock followed by resuscitation (HSR) causes neutrophil sequestration in the lung which leads to acute lung injury (ALI). Neutrophil elastase (NE) is thought to play a pivotal role in the pathogenesis of ALI. This study investigated whether sivelestat, a specific NE inhibitor, can attenuate ALI induced by HSR in rats. Male Sprague-Dawley rats were subjected to hemorrhagic shock by withdrawing blood so as to maintain a mean arterial blood pressure of $30 \pm 5 \mathrm{~mm} \mathrm{Hg}$ for $60 \mathrm{~min}$ followed by resuscitation with the shed blood. HSR-treated animals received a bolus injection of sivelestat $(10 \mathrm{mg} / \mathrm{kg})$ intravenously at the start of resuscitation followed by continuous infusion for $60 \mathrm{~min}$ $(10 \mathrm{mg} / \mathrm{kg} / \mathrm{h})$ during the resuscitation phase, or the vehicle. Lung injury was assessed by pulmonary histology, lung wetweight to dry-weight (W/D) ratio, myeloperoxidase (MPO) activity, gene expression of tumor necrosis factor (TNF)- $\alpha$ and inducible nitric oxide synthase (iNOS), DNA binding activity of nuclear factor (NF)- $\mathrm{kB}$, and immunohistochemical analysis of intercellular adhesion molecule (ICAM)-1. HSR treatment induced lung injury, as demonstrated by pulmonary edema with infiltration of neutrophils, the increase in lung W/D ratio, MPO activity, gene expression of TNF- $\alpha$ and iNOS, and DNA-binding activity of $\mathrm{NF}-\kappa \mathrm{B}$, and enhanced expression of ICAM-1. In contrast, sivelestat treatment significantly ameliorated the HSR-induced lung injury, as judged by the marked improvement in all these indices. These results indicate that sivelestat attenuated HSR-induced lung injury at least in part through an inhibition of the inflammatory signaling pathway, in addition to the direct inhibitory effect on NE.
\end{abstract}

Correspondence to: Dr Toru Takahashi, Department of Anesthesiology and Resuscitology, Okayama University Medical School, 2-5-1 Shikata-cho, Okayama, Okayama 700-8558, Japan

E-mail: takatoru@cc.okayama-u.ac.jp

Key words: acute lung injury, elastase inhibitor, hemorrhagic shock, inflammation, neutrophil

\section{Introduction}

Hemorrhagic shock followed by resuscitation (HSR) induces a systemic inflammatory response that leads to acute lung injury (ALI) $(1,2)$. ALI, associated with severe lung inflammation, is characterized by severe alveolar edema with large numbers of neutrophils in the alveoli and lung interstitium $(2,3)$. Despite recent progress in understanding the pathogenesis of ALI, no effective drug treatment has yet been established (4).

Neutrophil elastase (NE) is known to play a central role in the pathophysiology of ALI not only by causing direct tissue injury but also by amplifying the inflammatory response (5-7). Thus, inhibitors of NE are recognized as a potential therapeutic target against ALI (5-7). Recently, a small molecular weight NE inhibitor, sivelestat, has been shown to ameliorate ALI in various animal models (8-13). However, to our knowledge, the effect of sivelestat on ALI caused by HSR has not been reported. Moreover, the precise mechanism of the anti-inflammatory action of sivelestat on ALI has not been fully elucidated. In the present study, we administered sivelestat to a rat model of ALI induced by HSR (14) and examined its effect on lung injury. The degree of lung injury and inflammation was assessed by measurements of pulmonary histology, lung wet-weight to dry-weight (W/D) ratio, lung myeloperoxidase (MPO) activity, tumor necrosis factor (TNF)- $\alpha$, inducible nitric oxide synthase (iNOS) and intercellular adhesion molecule (ICAM)-1 mRNAs, immunohistochemical analysis of ICAM-1, and DNA binding activity

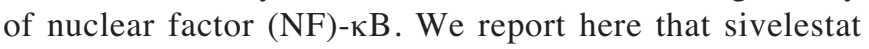
greatly ameliorates HSR-induced injury and inflammation of the lung. These findings also suggest that sivelestat suppresses the lung injury induced by HSR, at least in part, through attenuation of the inflammatory signaling pathway.

\section{Materials and methods}

This study was approved by the Animal Use and Care Committee of the Okayama University Medical School. Male Sprague-Dawley rats weighing 350-400 g were purchased from Charles River (Yokohama, Japan). They were housed 
in a temperature-controlled $\left(25^{\circ} \mathrm{C}\right)$ room with alternating 12 -h light/12-h dark cycles and were allowed free access to water and chow diet until the commencement of the experiments.

Hemorrhagic shock protocol. Rats were anesthetized with intraperitoneal sodium pentobarbital $(50 \mathrm{mg} / \mathrm{kg})$ and were then subjected to sham or hemorrhagic shock as described previously (14). In brief, the left femoral artery and the left femoral vein were dissected out using aseptic techniques and were cannulated with a heparinized polyethylene tube. Catheters were inserted into the left femoral artery for measurement of blood pressure, and the left femoral vein for the induction of hemorrhage. Hemorrhage was initiated by bleeding the animal into a heparinized syringe over a period of $15 \mathrm{~min}$ to achieve a mean arterial blood pressure of $30 \mathrm{~mm}$ $\mathrm{Hg}$. This level of blood pressure $(30 \pm 5 \mathrm{~mm} \mathrm{Hg})$ was maintained for 60 min either by further blood withdrawal or by reinfusing the shed blood. At this point, animals were resuscitated over $15 \mathrm{~min}$ by first returning all shed blood, followed by administering sterile saline as necessary. The sham group underwent all instrumentation procedures, but blood was not collected. Animals were allowed to breathe spontaneously throughout the experiment. To maintain body temperature within a physiological range, all procedures were performed over a heating pad with continuous monitoring of rectal body temperature. Electrocardiography was also measured continuously.

Experimental design. To examine the effects of sivelestat on HSR-induced lung injury, HSR rats were randomly assigned to the following three groups: control with sham operation (Sham group), vehicle-treated HSR animals (HSR/Vehicle group), and sivelestat-treated HSR animals (HSR/Sivelestat group). Sodium sivelestat $(50 \mathrm{mg})$, which was generously provided by Ono Pharmaceutical Co. (Osaka, Japan), was dissolved in $5 \mathrm{ml}$ of normal saline with $6.125 \mathrm{mg}$ of sodium carbonate as a $\mathrm{pH}$ adjustment. In the HSR/Sivelestat group, $10 \mathrm{mg} / \mathrm{kg}$ of sivelestat was administered as a bolus at the start of resuscitation followed by continuous infusion via the tail vein at $10 \mathrm{mg} / \mathrm{kg} / \mathrm{h}$ for $60 \mathrm{~min}$ during the resuscitation phase. This dose of sivelestat was chosen since it has been reported to be sufficient to inhibit neutrophil elastase activity (15). The same volume of $\mathrm{pH}$-adjusted normal saline was given to the HSR/Vehicle group. Animals were sacrificed by decapitation at each defined time point under anesthesia with the inhalational of ethyl ether. The lungs were harvested, excised and frozen immediately in liquid nitrogen and stored at $-80^{\circ} \mathrm{C}$ until use for the preparation of RNA, nuclear extracts and measurement of MPO activity.

cDNA probes. Template cDNAs for TNF- $\alpha$ and iNOS were prepared as described previously $(14,16)$. All probes used for Northern blot analysis were $\left[\alpha^{-}{ }^{32} \mathrm{P}\right] \mathrm{dCTP}$ (GE Healthcare Bio Sciences Corp., Piscataway, NJ)-labeled cDNA probes prepared by using a random primer DNA labeling system (GE Healthcare Bio Sciences Corp.) according to the manufacturer's instructions $(14,16)$.

RNA isolation and Northern blot analysis. Total RNA was isolated from the rat lungs using Tri-Reagent ${ }^{\mathrm{TM}}$ (Sigma
Chemical Co., St. Louis, MO) according to the manufacturer's protocol. Northern blotting was performed as described previously (17). Twenty micrograms of total RNA was subjected to electrophoresis in a $1.2 \%(\mathrm{w} / \mathrm{v})$ agarose gel containing $6.5 \%(\mathrm{v} / \mathrm{v})$ formaldehyde. After blotting on a sheet of Bio-Rad Zeta-Probe membrane (Bio-Rad Laboratories, Richmond, CA), RNA samples were hybridized with $\left[\alpha-{ }^{32} \mathrm{P}\right] \mathrm{dCTP}-$ labeled cDNA probes followed by washing under stringent conditions. The membrane was exposed to a sheet of Fuji Medical radiograph film with an intensifying screen at $-70^{\circ} \mathrm{C}$, and autoradiographs and $18 \mathrm{~S}$ ribosomal RNA were quantified using an image scanner (GelPrint ${ }^{\mathrm{TM}}$ 2000i, Genomic Solutions, Ann Arbor, MI) and a computerized image analysis software package (Basic Quantifier ${ }^{\mathrm{TM}}$ version 3.0, Genomic Solutions). The relative amounts of radiolabelled cDNA that hybridized to the blots were normalized to the $18 \mathrm{~S}$ ribosomal RNA levels for loading errors.

\section{Real-time reverse transcription-polymerase chain reaction} (RT-PCR). Real-time RT-PCR analysis was performed as described previously with some modifications (18). Briefly, total RNA was extracted from lung tissue as described above and then poly $(\mathrm{A})^{+}$RNA was isolated using Oligotex ${ }^{\mathrm{TM}}$ dT30 (Takara, Tokyo, Japan). The first-strand cDNA was generated by reverse transcription reaction using MMLV reverse transcriptase (Invitrogen, Carlsbad, CA) and the poly $(\mathrm{A})^{+}$ RNA preparations as templates. The cDNA was amplified by RT-PCR by using a Light Cycler (Roche Diagnostics, Indianapolis, IN) with the specific upstream and downstream primers for ICAM-1 mRNA analysis under the following reaction conditions: denaturation at $95^{\circ} \mathrm{C}$ for $10 \mathrm{~min}$, followed by 40 cycles of denaturation at $95^{\circ} \mathrm{C}$ for $10 \mathrm{sec}$, annealing at $60^{\circ} \mathrm{C}$ for $10 \mathrm{sec}$, and extension at $72^{\circ} \mathrm{C}$ for $8 \mathrm{sec}$. The sequences of the upstream and downstream primers for ICAM-1 and $\beta$-actin were as follows: 5'-CAAACGGGAG ATGAATGGTA-3' and 5'-AATAGGTGTAAATGGACGC C-3' for ICAM-1; and 5'-CCTGTATGCCTCTGGTCGTA-3' and 5'-CCATCTCTTGCTCGAAGTCT-3' for $B$-actin, respectively. The product sizes were $176 \mathrm{bp}$ for ICAM-1 and $260 \mathrm{bp}$ for B-actin, respectively. The amplified products were analyzed by melting curve analysis and stained using SYBRGreen I. The ICAM-1 mRNA level was normalized with the $\beta$-actin mRNA level in each poly $(\mathrm{A})^{+} \mathrm{RNA}$ preparation.

Preparation of nuclear extracts and electrophoretic mobility shift assay. Nuclear extracts were prepared from frozen lung sections as described by Dignam and colleagues (19), with some modifications (20). Nuclear extracts were incubated with a $\left[\gamma^{-32} \mathrm{P}\right] \mathrm{ATP}$ (GE Healthcare Bio Sciences Corp.)-labeled NF-кB consensus oligonucleotide probe (5'-AGTTGAGGG GACTTTCCCAGGC-3') (21) in a total volume of $10 \mu 1$ of binding buffer (10 mM Tris- $\mathrm{HCl}, \mathrm{pH} 7.5,50 \mathrm{mM} \mathrm{NaCl}, 1 \mathrm{mM}$ $\mathrm{MgCl}_{2}, 0.5 \mathrm{mM}$ EDTA, $0.5 \mathrm{mM}$ DTT, $4 \%$ glycerol, and $0.5 \mu \mathrm{g}$ polydI:dC) at room temperature for $20 \mathrm{~min}$ according to the manufacturer's instructions (Promega, Madison, WI). Following the incubation, the reaction mixture was subjected to electrophoresis in nondenaturing $5 \%$ polyacrylamide gel. The gels were vacuum-dried and exposed to X-ray film at $-70^{\circ} \mathrm{C}$. Self-competitions were carried out under the same conditions using a 100-fold excess of the unlabeled NF-кB 

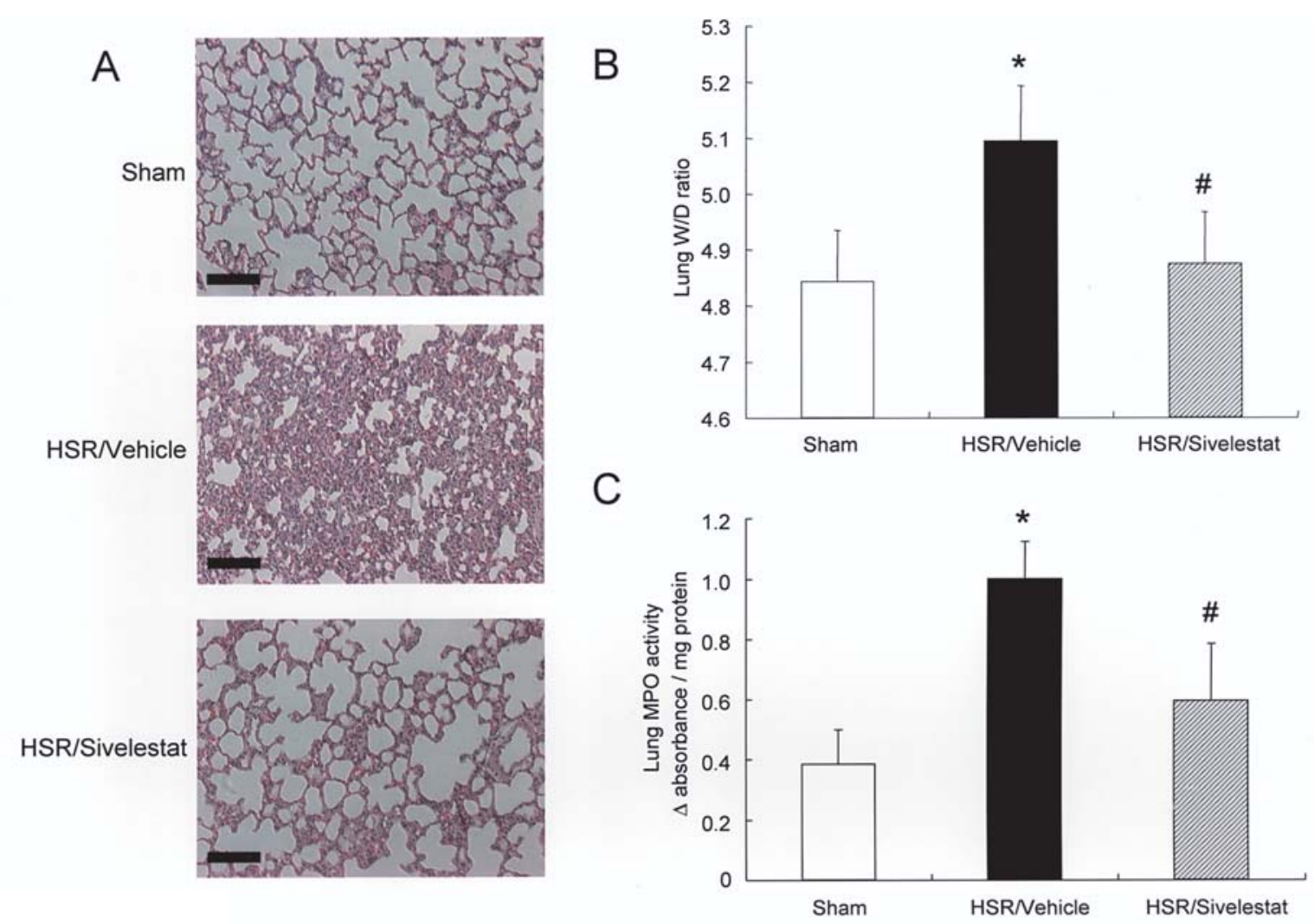

Figure 1. Effect of sivelestat treatment on histologic changes, wet-weight to dry-weight (W/D) ratio and myeloperoxidase (MPO) activity of the lung after hemorrhagic shock followed by resuscitation (HSR). Rats subjected to HSR were administered sivelestat or vehicle intravenously at the start of resuscitation $(10 \mathrm{mg} / \mathrm{kg}$ ) followed by continuous infusion for $1 \mathrm{~h}$ at $10 \mathrm{mg} / \mathrm{kg} / \mathrm{h}$. Lungs were excised at $12 \mathrm{~h}$ after HSR and used for histologic examination (A), measurement of W/D ratio (B) and MPO activity (C) as described in Materials and methods. (A) Each photograph is the representative of at least three independent experiments. Bars, $100 \mu \mathrm{m}$. Sections were stained with hematoxylin and eosin. For B and C data are presented as means $\pm \mathrm{SD}$ ( $\mathrm{n}=5$ for each group). Statistical analysis was carried out by analysis of variance with Scheffé's F-test. ${ }^{*} \mathrm{P}<0.01$ vs Sham; ${ }^{\# P}<0.01$ vs HSR/Vehicle. Sham, sham-operated control animals; HSR/Vehicle, HSR with vehicle treatment; and HSR/Sivelestat, HSR with sivelestat treatment.

oligonucleotide probe. Nonspecific competitions were similarly performed using an unlabeled oligonucleotide probe encompassing an OCT1 transcription factor binding site (5'-TGTCGAATGCAAATCACTAGAA-3') (22). Autoradiographs were quantified as described above.

Histological study. For histological examination, the left lower lobe of the lung was fixed in $10 \%$ neutral-buffered formalin, embedded in paraffin, and sectioned at 4- to 6- $\mu \mathrm{m}$ thicknesses. After deparaffinization and dehydration, the sections were stained with hematoxylin and eosin for microscopic examination. For immunohistochemical analysis, the enzymatic activity of the endogenous peroxidases in the lung section was first blocked with $3 \%$ hydrogen peroxide, followed by incubation with a goat polyclonal anti-rat ICAM-1 antibody (R\&D Systems, Inc., Minneapolis, MN) at $4^{\circ} \mathrm{C}$ for $16 \mathrm{~h}$. The antigen-antibody reaction was detected using an anti-goat secondary antibody and an avidin-biotin immunoperoxidase staining kit (Dako, Carpinteria, CA). The positive reaction was visualized as a brown stain following treatment with 3,3-diaminobenzidine. Normal rabbit serum was used as control for nonspecific staining. Sections were counterstained with Mayer's hematoxylin solution.

Lung MPO activity. Lung MPO activity was measured as described by Bradley et al (23), with some modifications (14).
Briefly, tissue was homogenized in $50 \mathrm{mM}$ potassium phosphate buffer ( $\mathrm{pH} 6.0$ ) containing $0.5 \%(\mathrm{w} / \mathrm{v})$ hexadecyltrimethylammonium bromide (Nacalai Tesque Inc., Tokyo, Japan) followed by centrifugation at $15,000 \mathrm{x} g$ for $15 \mathrm{~min}$ at $4^{\circ} \mathrm{C}$. After centrifugation, $0.1 \mathrm{ml}$ of the supernatant was mixed with $2.9 \mathrm{ml}$ of $50 \mathrm{mM}$ potassium phosphate buffer (pH 6.0) containing $0.167 \mathrm{mg} / \mathrm{ml} o$-dianisidine dehydrochloride (Sigma Chemical Co.). Following the addition of $5 \mu 1$ of $0.3 \%$ hydrogen peroxide to the mixture, the increase in color was monitored at $460 \mathrm{~nm}$ for $1 \mathrm{~min}$ on a spectrophotometer $\left(\mathrm{U}-3000^{\mathrm{TM}}\right.$, Hitachi, Tokyo, Japan). The protein concentration of the supernatant was determined by the method of Lowry (24). Values are reported as the change in O.D. ( $\Delta$ O.D.) per $\mathrm{mg}$ of protein.

Lung W/D ratio. Right lung tissue samples were blotted, weighed, then dried at $110^{\circ} \mathrm{C}$ for $24 \mathrm{~h}$. The dry tissue weight was then determined and W/D ratios were calculated as an index of pulmonary edema (25).

Statistical analysis. Statistical evaluation was performed with analysis of variance (ANOVA) followed by the Scheffé's Ftest. Data are presented as means $\pm \mathrm{SD}$. Comparisons were made using Statview software (Abacus Concepts, Berkeley, CA). A P value $<0.05$ was considered to be statistically significant. 

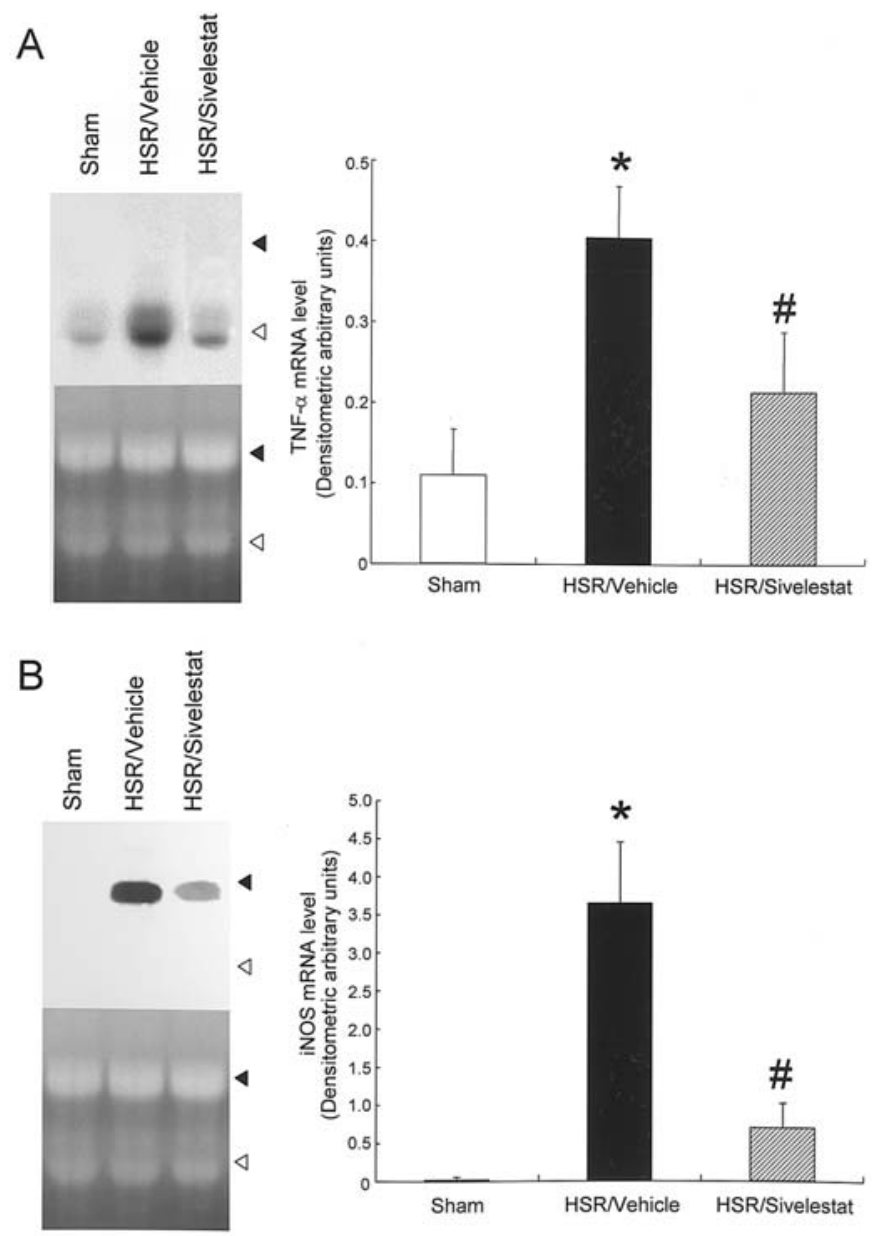

Figure 2. Effect of sivelestat treatment on gene expression of pulmonary tumor necrosis factor (TNF)- $\alpha$ and inducible nitric oxide synthase (iNOS) after hemorrhagic shock followed by resuscitation (HSR). Rats subjected to HSR were administered sivelestat or vehicle intravenously at the start of resuscitation $(10 \mathrm{mg} / \mathrm{kg})$ followed by continuous infusion for $1 \mathrm{~h}$ at $10 \mathrm{mg} /$ $\mathrm{kg} / \mathrm{h}$. Lungs were excised at $3 \mathrm{~h}$ after HSR for Northern blot analysis as described in Materials and methods. Left: $20 \mu \mathrm{g}$ of total RNA was subjected to Northern blot analysis. Representative autoradiographic signals of RNA blot hybridized with $\left[\alpha^{-32} \mathrm{P}\right] \mathrm{dCTP}-$ labeled TNF- $\alpha$ (A) or iNOS (B) cDNA with ethidium bromide staining gel as a loading control of five independent experiments. Filled arrowhead, 28S ribosomal RNA; open arrowhead, 18S ribosomal RNA. Sham, sham-operated control animals; HSR/Vehicle, HSR with vehicle treatment; and HSR/Sivelestat, HSR with sivelestat treatment. Right: the levels of TNF- $\alpha$ (A) or iNOS (B) mRNA are expressed as means \pm SD of densitometric arbitrary units $(n=5$ for each group). Statistical analysis was performed by analysis of variance with Scheffé's F-test. ${ }^{*} \mathrm{P}<0.01$ vs Sham; ${ }^{*} \mathrm{P}<0.01$ vs HSR/Vehicle.

\section{Results}

Effects of sivelestat treatment on histological changes, W/D ratio and MPO activity of the lung after HSR. We examined the effect of sivelestat treatment on lung injury after HSR. Lung injury was assessed by morphological examination, with the W/D ratio as an index of pulmonary edema (25), and lung MPO activity as a measure of pulmonary neutrophil content (26). Sections of lung excised from sham-operated control animals were essentially normal (Fig. 1A, top). In contrast, HSR/Vehicle animals exhibited pronounced alveolar septal thickening with marked infiltration of inflammatory cells at $12 \mathrm{~h}$ after HSR (Fig. 1A, middle) (14). Consistent with the histological findings, the lung W/D ratio (Fig. 1B) and lung MPO activity (Fig. 1C) at $12 \mathrm{~h}$ after HSR were significantly increased compared with that of the shamoperated control animals (14). In contrast, sivelestat treatment greatly suppressed lung injury, as revealed by the reduced histological damage (Fig. 1A, bottom), the marked decrease in lung W/D ratio, which reached the same level as the shamoperated control animals (Fig. 1B), and the significant reduction in MPO activity (Fig. 1C). Thus, these findings indicate that sivelestat treatment greatly improves lung injury induced by HSR.

Effect of sivelestat treatment on TNF- $\alpha$ and iNOS gene expression after HSR. Since sivelestat treatment significantly ameliorated HSR-induced lung injury, next we examined the effect of sivelestat treatment on TNF- $\alpha$ gene expression, a pro-inflammatory cytokine. Pulmonary TNF- $\alpha$ mRNA was slightly detected in sham-operated control animals, while it increased significantly in HSR/Vehicle animals at $3 \mathrm{~h}$ after HSR (Fig. 2A) (14). In contrast, the TNF- $\alpha$ mRNA level in HSR/Sivelestat animals markedly decreased to $\sim 50 \%$ of the level of the HSR/Vehicle animals (Fig. 2A). Since iNOS is known to be upregulated in NO-induced inflammatory tissue injuries $(27,28)$, we also examined the effect of sivelestat treatment on iNOS gene expression in the lung after HSR. Similar to the changes in TNF- $\alpha$ gene expression, at $3 \mathrm{~h}$ after HSR, pulmonary iNOS mRNA level significantly increased in the HSR/Vehicle animals whereas its level in sham-operated animals remained barely detectable (Fig. 2B) (14). In contrast, its level in HSR/Sivelestat animals was markedly decreased, to $\sim 20 \%$ of the level in HSR/Vehicle animals (Fig. 2B). Thus, HSR-induced pulmonary inflammation was markedly attenuated by sivelestat treatment.

Effects of sivelestat treatment on ICAM-1 expression in the lung after HSR. Since cell adhesion molecules play pivotal roles in pulmonary inflammation by the recruitment of leukocytes into the lung $(29,30)$, we then examined the effect of sivelestat treatment on gene expression of ICAM-1, an important cell adhesion molecule (29), in the lung after HSR. The ICAM-1 mRNA level was detectable in sham-operated control animals whereas it was markedly increased in the HSR/Vehicle animals (Fig. 3A) (31). In contrast, in HSR/ Sivelestat animals the level was significantly decreased, to almost the same as that of the sham-operated control animals (Fig. 3A). We also carried out immunohistochemical analysis of ICAM-1 in the lung from rats at $12 \mathrm{~h}$ after HSR, to determine what type of cells in the lung expressed ICAM-1. Lung sections obtained from sham-operated control animals stained with anti-ICAM-1 antibody exhibited a low but constitutive level of staining along the vascular endothelium and alveolar epithelium (Fig. 3B, top). Following HSR, the staining intensity of ICAM-1 was substantially increased along the vascular endothelium (Fig. 3B, middle) (32). In contrast, a marked reduction in ICAM-1 immunostaining was observed in the lung sections from the HSR/Sivelestat animals (Fig. 3B, bottom). Sections of the lung from HSR/Vehicle rats displayed no signal when treated with non-immune goat serum (data not shown). 


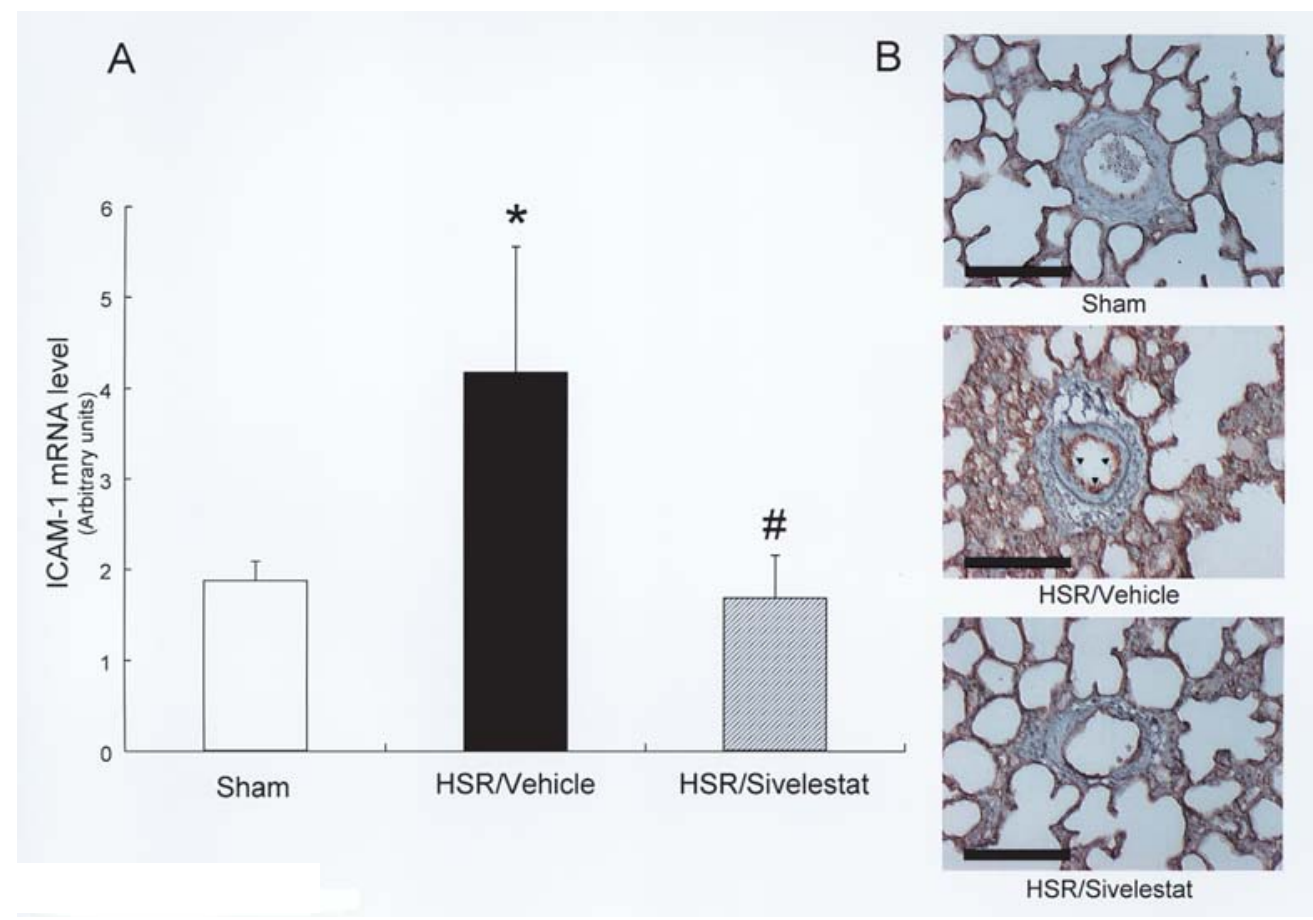

Figure 3. Effects of sivelestat treatment on expression of intercellular adhesion molecule (ICAM)-1 after hemorrhagic shock followed by resuscitation (HSR). Rats subjected to HSR were administered sivelestat or vehicle intravenously at the start of resuscitation ( $10 \mathrm{mg} / \mathrm{kg}$ ) followed by continuous infusion for $1 \mathrm{~h}$ at $10 \mathrm{mg} / \mathrm{kg} / \mathrm{h}$. (A) Lungs were excised at $3 \mathrm{~h}$ after HSR for the measurement of ICAM-1 mRNA levels using RT-PCR analysis as described in Materials and methods. The levels of ICAM-1 mRNA are expressed as the mean \pm SD of densitometric arbitrary units ( $n=5$ for each group). Sham, sham-operated control animals; HSR/Vehicle, HSR with vehicle treatment; and HSR/Sivelestat, HSR with sivelestat treatment. Statistical analysis was conducted by analysis of variance with Scheffé's F-test. ${ }^{*} \mathrm{P}<0.05$ vs Sham; ${ }^{\#} \mathrm{P}<0.05$ vs HSR/Vehicle. (B) Lung sections from $12 \mathrm{~h}$ after HSR were used for immunohistochemical detection of ICAM-1 using a goat polyclonal anti-rat ICAM-1 as the primary antibody. Immunohistochemical staining was carried out as described in Materials and methods. Arrowheads indicate intensely stained vascular endothelial cells. Each photograph represents at least three independent experiments. Bars, $100 \mu \mathrm{m}$.

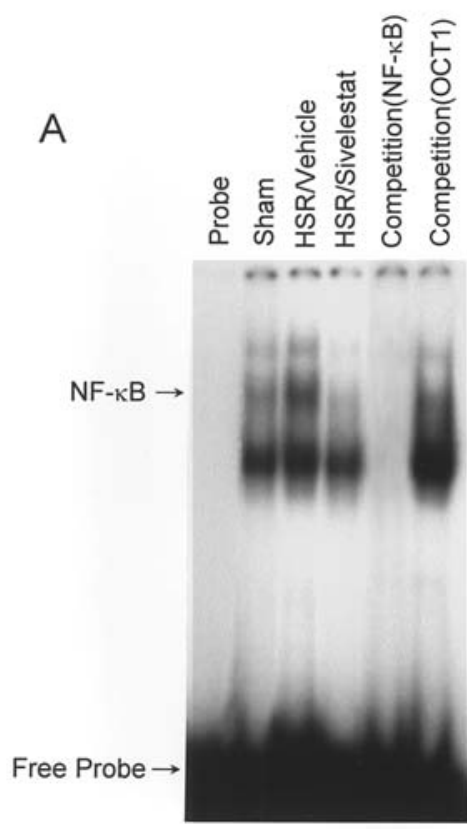

B

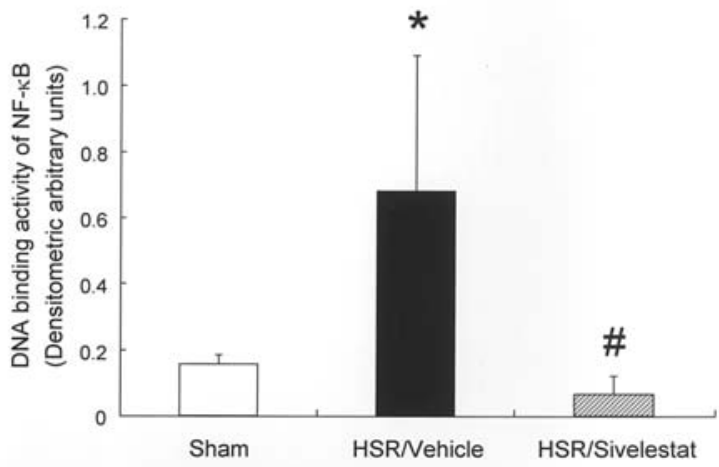

Figure 4. Activation of nuclear factor (NF)-kB binding by hemorrhagic shock followed by resuscitation (HSR) and its modulation by sivelestat treatment. Rats subjected to HSR were administered sivelestat or vehicle intravenously at the start of resuscitation $(10 \mathrm{mg} / \mathrm{kg})$ followed by continuous infusion for $1 \mathrm{~h}$ at $10 \mathrm{mg} / \mathrm{kg} / \mathrm{h}$. DNA binding activity of NF-kB was analyzed by electrophoretic mobility shift assay at $1.5 \mathrm{~h}$ after HSR as described in Materials and methods. (A) Representative autoradiographic signals of three independent experiments. Probe, a probe without nuclear extract; Sham, sham-operated control animals; HSR/Vehicle, HSR with vehicle treatment; HSR/Sivelestat, HSR with sivelestat treatment; Competition (NF-kB), HSR/Vehicle with the addition of 100-fold excess of unlabeled NF-kB oligonucleotide; Competition (OCT1), HSR/Vehicle with the addition of 100-fold excess of unlabeled OCT1 oligonucleotide. (B) The levels of NF-kB activity are expressed as means \pm SD of densitometric arbitrary units ( $\mathrm{n}=3$ for each group). Statistical analysis was performed by analysis of variance with Scheffé's F-test. ${ }^{*} \mathrm{P}<0.05$ vs Sham; ${ }^{*} \mathrm{P}<0.01$ vs HSR/Vehicle. 
Effects of sivelestat treatment on the DNA binding activity of $N F-\kappa B$ after HSR. Since activation of the promoters of the TNF- $\alpha$, iNOS and ICAM-1 genes are known to be mediated in part by the activation of the transcription factor $\mathrm{NF}-\kappa \mathrm{B}$ $(33,34)$, we also examined the effect of sivelestat treatment on the DNA binding activity of $\mathrm{NF}-\kappa \mathrm{B}$. The DNA binding activity of NF- $\kappa \mathrm{B}$ was only slightly detectable in the lungs of sham-operated control animals (Fig. 4) (35). A significant NF-кB DNA binding activity was, however, detected in the lung at $1.5 \mathrm{~h}$ after HSR (Fig. 4) (35). On the other hand, this activity was markedly attenuated when animals were additionally treated with sivelestat. The activity was also specific to the NF- $\mathrm{KB}$ DNA binding motif, since the binding activity was completely abolished by incubation with an unlabelled NF-кB oligonucleotide, but not with an unrelated probe, such as an unlabeled oligonucleotide specific to the OCT1 transcription factor (Fig. 4).

\section{Discussion}

The present study demonstrates that treatment with the specific NE inhibitor sivelestat during the resuscitation phase after hemorrhagic shock attenuates HSR-induced lung injury and inflammation. The findings also indicate that sivelestat markedly suppresses the molecular activation of the inflammatory cascade induced by HSR. These results suggest that, in addition to the inhibitory effect on NE activity, sivelestat may protect the lung from HSR-induced tissue injury, mediated at least in part through the inhibition of the inflammatory cellular signaling pathway activated by HSR.

HSR caused severe lung injury with the characteristic features of ALI, as revealed by the evidence of alveolar septal thickening due to interstitial edema with infiltration of inflammatory cells (Fig. 1A), which was confirmed by the increase in lung W/D ratio and MPO activity, respectively (Fig. 1B and C) (14). In contrast, sivelestat treatment markedly ameliorated the HSR-induced lung injury, as shown by the lesser tissue injury compared with that observed in the HSR/ Vehicle animals, with a large reduction of these indices (Fig. 1). These findings suggest that NE may play an important role in the development of ALI following HSR. In agreement with our findings, previous reports indicated that NE plays a central role in the development of other models of ALI (5-7) including those caused by endotoxin administration $(8,9)$, exposure to hyperoxia $(10)$, and ischemia-reperfusion $(11,12)$, and that a selective inhibitor of NE, sivelestat, ameliorates the condition in these models of ALI (8-13).

HSR is known to cause pulmonary inflammation in association with neutrophil sequestration in the pulmonary microvasculature, followed by adhesion and activation (2). Consistent with this notion, following HSR, the mRNA levels of TNF- $\alpha$ as well as iNOS, both of which play a pivotal role in the inflammatory response after HSR, markedly increased in the lung (Fig. 2) (14). Moreover, expression of ICAM-1, which is an important adhesion molecule for neutrophil activation, markedly increased in the vascular endothelium after HSR (Fig. 3) (32). In contrast, sivelestat treatment of HSR animals significantly attenuated the expression of these proinflammatory molecules compared with HSR alone (Figs. 2 and 3). Thus, these findings suggest that sivelestat possesses potent anti-inflammatory properties, and hence is able to suppress HSR-induced pulmonary tissue inflammation and injury.

The molecular mechanism(s) behind the suppressive effect of sivelestat on the expression of proinflammatory molecules is unclear and remains to be determined. However, it has been reported that $\mathrm{NE}$ acts to up-regulate the gene expression of IL-8, a proinflammatory chemokine, through the IL-1 receptor-associated kinase intracellular signaling pathway, resulting in the activation of NF-кB (36). Another study also has shown that NE up-regulates IL-8 via toll-like receptor 4 (TLR4) (37). Moreover, enzymatic degradation by elastase of heparin sulfate proteoglycans, a component of all cell surfaces and extracellular matrices, has been shown to activate TLR4 to induce a systemic inflammatory response (38). The pleiotropic transcription factor $N F-\kappa B$ plays a crucial role in regulating the expression of proinflammatory molecules including TNF- $\alpha$, iNOS and ICAM-1 $(33,34)$. Our results also demonstrate that HSR markedly increases NF-кB activity after HSR in the lung (35), whereas treatment with sivelestat significantly attenuated it (Fig. 4). Taken together, one can hypothesize that sivelestat inhibits the activity of $\mathrm{NE}$ to degrade the components of the cell surface and extracellular matrix, thereby decreasing the production of ligands of TLR4, such as heparin sulfate proteoglycans. This in turn results in the suppression of TLR4-mediated NF- $\mathrm{B}$ activation, leading to the attenuation of expression of these proinflammatory molecules.

In conclusion, this study demonstrates that NE plays an important role in the development of HSR-induced ALI. It is also demonstrated that sivelestat, a specific inhibitor for NE, ameliorated HSR-induced ALI at least in part by attenuating the molecular activation of the inflammatory cascade induced by HSR. Sivelestat has been reported to ameliorate various animal models of ALI caused by systemic inflammatory response (13). However, the efficacy of sivelestat as a treatment for ALI in the clinical setting is still a matter of controversy $(13,39)$. Given the fact that pulmonary inflammation contributes significantly to the pathogenesis of ALI $(2,3)$, these findings may help to determine the intelligent use of sivelestat as a drug in the anti-inflammatory strategy for the treatment of ALI, although further studies are clearly needed.

\section{Acknowledgements}

This study was in part supported by grants from Grant-in-Aid for Scientific Research no. 17591888 from the Ministry of Education, Culture, Sports, Science, and Technology of Japan. We are grateful to Ono Pharmaceutical Co. (Osaka, Japan) who kindly provided sivelestat for this study. We are also grateful to Dr Yohji Wani (Kurashiki Central Hospital, Kurashiki, Japan) for his helpful discussions. Pacific Edit reviewed the manuscript prior to submission.

\section{References}

1. Jarrar D, Chaudry IH and Wang P: Organ dysfunction following hemorrhage and sepsis: mechanisms and therapeutic approaches (Review). Int J Mol Med 4: 575-583, 1999.

2. Bhatia M and Moochhala S: Role of inflammatory mediators in the pathophysiology of acute respiratory distress syndrome. J Pathol 202: 145-156, 2004. 
3. Ware LB and Matthay MA: The acute respiratory distress syndrome. N Engl J Med 342: 1334-1349, 2000.

4. Wiedemann HP, Arroliga AC and Komara JJ Jr: Emerging systemic pharmacologic approaches in acute respiratory distress syndrome. Respir Care Clin N Am 9: 419-435, 2003.

5. Kawabata K, Hagio T and Matsuoka S: The role of neutrophil elastase in acute lung injury. Eur J Pharmacol 451: 1-10, 2002.

6. Moraes TJ, Chow CW and Downey GP: Proteases and lung injury. Crit Care Med 31: S189-S194, 2003.

7. Lee WL and Downey GP: Leukocyte elastase: physiological functions and role in acute lung injury. Am J Respir Crit Care Med 164: 896-904, 2001.

8. Kawabata K, Hagio T, Matsumoto S, Nakao S, Orita S, Aze Y and Ohno H: Delayed neutrophil elastase inhibition prevents subsequent progression of acute lung injury induced by endotoxin inhalation in hamsters. Am J Respir Crit Care Med 161: 2013-2018, 2000.

9. Nishina K, Mikawa K, Takao Y, Maekawa N, Shiga M and Obara H: ONO-5046, an elastase inhibitor, attenuates endotoxin-induced acute lung injury in rabbits. Anesth Analg 84: 1097-1103, 1997

10. Yamamoto H, Koizumi T, Kaneki T, Hanaoka M and Kubo K: Effects of lecithinized superoxide dismutase and a neutrophil elastase inhibitor (ONO-5046) on hyperoxic lung injury in rat. Eur J Pharmacol 409: 179-183, 2000.

11. Yamazaki T, Ooshima H, Usui A, Watanabe T and Yasuura K: Protective effects of ONO-5046* $\mathrm{Na}$, a specific neutrophil elastase inhibitor, on postperfusion lung injury. Ann Thorac Surg 68: 2141-2146, 1999.

12. Tomizawa N, Ohwada S, Ohya T, Takeyoshi I, Ogawa T, Kawashima Y, Adachi M and Morishita Y: The effects of a neutrophil elastase inhibitor (ONO-5046.Na) and neutrophil depletion using a granulotrap (G-1) column on lung reperfusion injury in dogs. J Heart Lung Transplant 18: 637-645, 1999.

13. Zeiher BG, Matsuoka S, Kawabata K and Repine JE: Neutrophil elastase and acute lung injury: prospects for sivelestat and other neutrophil elastase inhibitors as therapeutics. Crit Care Med 30: S281-S287, 2002.

14. Maeshima K, Takahashi T, Uehara K, Shimizu H, Omori E, Yokoyama M, Tani T, Akagi R and Morita K: Prevention of hemorrhagic shock-induced lung injury by heme arginate treatment in rats. Biochem Pharmacol 69: 1667-1680, 2005.

15. Jian MY, Koizumi T, Tsushima K, Fujimoto K and Kubo K: Effects of granulocyte colony-stimulating factor (G-CSF) and neutrophil elastase inhibitor (ONO-5046) on acid-induced lung injury in rats. Inflammation 28: 327-336, 2004.

16. Fujii H, Takahashi T, Nakahira K, Uehara K, Shimizu H, Matsumi M, Morita K, Hirakawa M, Akagi R and Sassa S: Protective role of heme oxygenase- 1 in the intestinal tissue injury in an experimental model of sepsis. Crit Care Med 31: 893-902, 2003.

17. Kawakami T, Takahashi T, Shimizu H, Nakahira K, Takeuchi M, Katayama H, Yokoyama M, Morita K, Akagi R and Sassa S: Highly liver-specific heme oxygenase- 1 induction by interleukin-11 prevents carbon tetrachloride-induced hepatotoxicity. Int J Mol Med 18: 537-546, 2006.

18. Kojima N, Sato M, Suzuki A, Sato T, Satoh S, Kato T and Senoo H: Enhanced expression of B7-1, B7-2, and intercellular adhesion molecule 1 in sinusoidal endothelial cells by warm ischemia/reperfusion injury in rat liver. Hepatology 34: 751-757, 2001.

19. Dignam JD, Lebovitz RM and Roeder RG: Accurate transcription initiation by RNA polymerase II in a soluble extract from isolated mammalian nuclei. Nucleic Acids Res 11: 1475-1489, 1983.

20. Nakahira K, Takahashi T, Shimizu H, Maeshima K, Uehara K, Fujii H, Nakatsuka H, Yokoyama M, Akagi R and Morita K: Protective role of heme oxygenase-1 induction in carbon tetrachloride-induced hepatotoxicity. Biochem Pharmacol 66: 1091-1105, 2003.
21. Lenardo MJ and Baltimore D: NF-kappa B: a pleiotropic mediator of inducible and tissue-specific gene control. Cell 58: 227-229, 1989.

22. O'Neill EA, Fletcher C, Burrow CR, Heintz N, Roeder RG and Kelly TJ: Transcription factor OTF-1 is functionally identical to the DNA replication factor NF-III. Science 241: 1210-1213, 1988

23. Bradley PP, Priebat DA, Christensen RD and Rothstein G: Measurement of cutaneous inflammation: estimation of neutrophil content with an enzyme marker. J Invest Dermatol 78: 206-209, 1982.

24. Lowry O: Protein measurement with the folin phenol reagent. J Biol Chem 193: 265-275, 1951.

25. Stephens KE, Ishizaka A, Larrick JW and Raffin TA: Tumor necrosis factor causes increased pulmonary permeability and edema. Comparison to septic acute lung injury. Am Rev Respir Dis 137: $1364-1370,1988$.

26. Goldblum SE, Wu KM and Jay M: Lung myeloperoxidase as a measure of pulmonary leukostasis in rabbits. J Appl Physiol 59: 1978-1985, 1985.

27. Szabo C and Billiar TR: Novel roles of nitric oxide in hemorrhagic shock. Shock 12: 1-9, 1999

28. Hierholzer C, Harbrecht B, Menezes JM, Kane J, MacMicking J, Nathan CF, Peitzman AB, Billiar TR and Tweardy DJ: Essential role of induced nitric oxide in the initiation of the inflammatory response after hemorrhagic shock. J Exp Med 187: 917-928, 1998.

29. Albelda SM, Smith CW and Ward PA: Adhesion molecules and inflammatory injury. FASEB J 8: 504-512, 1994.

30. Pilewski JM and Albelda SM: Adhesion molecules in the lung. An overview. Am Rev Respir Dis 148: S31-S37, 1993.

31. Hierholzer C, Menezes JM, Ungeheuer A, Billiar TR, Tweardy DJ and Harbrecht BG: A nitric oxide scavenger protects against pulmonary inflammation following hemorrhagic shock. Shock 17: 98-103, 2002

32. Alam HB, Austin B, Koustova E and Rhee P: Resuscitationinduced pulmonary apoptosis and intracellular adhesion molecule-1 expression in rats are attenuated by the use of Ketone Ringer's solution. J Am Coll Surg 193: 255-263, 2001.

33. Pahl HL: Activators and target genes of Rel/NF-kappaB transcription factors. Oncogene 18: 6853-6866, 1999.

34. Zingarelli B: Nuclear factor-kappaB. Crit Care Med 33: S414-S416, 2005.

35. Sasaki T, Takahashi T, Maeshima K, Shimizu H, Toda Y, Morimatsu H, Takeuchi M, Yokoyama M, Akagi R and Morita K: Heme arginate pretreatment attenuates pulmonary NF-kappaB and AP-1 activation induced by hemorrhagic shock via heme oxygenase-1 induction. Med Chem 2: 271-274, 2006

36. Walsh DE, Greene CM, Carroll TP, Taggart CC, Gallagher PM, O'Neill SJ and McElvaney NG: Interleukin-8 up-regulation by neutrophil elastase is mediated by MyD88/IRAK/TRAF-6 in human bronchial epithelium. J Biol Chem 276: 35494-35499, 2001.

37. Devaney JM, Greene CM, Taggart CC, Carroll TP, O'Neill SJ and McElvaney NG: Neutrophil elastase up-regulates interleukin-8 via toll-like receptor 4. FEBS Lett 544: 129-132, 2003.

38. Johnson GB, Brunn GJ and Platt JL: Cutting edge: an endogenous pathway to systemic inflammatory response syndrome (SIRS)like reactions through Toll-like receptor 4. J Immunol 172: 20-24, 2004.

39. Zeiher BG, Artigas A, Vincent JL, Dmitrienko A, Jackson K, Thompson BT and Bernard G: Neutrophil elastase inhibition in acute lung injury: results of the STRIVE study. Crit Care Med 32: 1695-1702, 2004. 